\title{
Risk factors for variant Creutzfeldt-Jakob disease in dental practice: a case-control study
}

\author{
A. M. Molesworth, ${ }^{1}$ A. J. Smith, ${ }_{1}^{2}$ D. Everington, ${ }_{1}^{3}$ F. Ord, ${ }_{1}^{4}$ P. Watt, ${ }_{1}^{5}$ \\ R. G. Will ${ }^{6}$ and H. J. T. Ward ${ }^{7}$
}

Objective To assess the risk of variant Creutzfeldt-Jakob Disease (VCJD) associated with dental treatment. Design Casecontrol study, investigation of links between cases. Setting National CJD surveillance, general dental practice and practice boards in Great Britain, 2008-2009. Methods Variant CJD cases were recruited from all those referred between May 1995 and August 2009 ( $n=160)$; controls were recruited from the general population in 2003 using randomly selected geographic clusters and age-weighted sampling of individuals $(n=584)$. Risk factors were ascertained from dental records, with consent, using a structured questionnaire. Results Dental records were available for fewer cases (49\%, 78 out of 160) than control subjects (78\%, 457 out of 584). Variant CJD cases were no more or less likely than control subjects to have undergone dental treatment $(p \geq 0.05$ ). Two cases had attended the same dental practice, but the type and timing of treatments did not provide strong evidence that this was linked to the route of transmission. Conclusion There is no evidence of a VCJD risk associated with dental treatment, but because dental information is limited we cannot exclude this possibility. Improved methods for dental record keeping are recommended to aid future investigations of associations between infectious diseases and dental treatment.

\section{INTRODUCTION}

Variant Creutzfeldt-Jakob disease (vCJD) was first reported in the United Kingdom in 1996, rising to 176 cases by March 2012. The number of infected individuals is estimated between 1 in 2,000..$^{1,2}$ Although consumption of bovine spongiform encephalopathy (BSE) contaminated meat products remains the most likely route by which humans became infected, ${ }^{3}$ the potential for transmission of vCJD via blood ${ }^{4,5}$ and evidence of nosocomial transmission of pathogens in dentistry, ${ }^{6,7}$ suggest dentistry also needs to be considered.

In the UK, there have been no known or suspected cases of vCJD transmission

\footnotetext{
"Senior Epidemiologist, National CJD Research and Surveillance Unit, University of Edinburgh, Western General Hospital, Edinburgh, EH4 2XU; ${ }^{2}$ Professor of Clinical Microbiology, College of Medical, Veterinary and Life Sciences, University of Glasgow, 378 Sauchiehall Street, Glasgow, G2 3JZ; ${ }^{3}$ Statistician, ${ }^{4}$ Dental Hygienist, ${ }^{5}$ Dental Hygienist, ${ }^{6}$ Professor of Neurology, ${ }^{7}$ Consultant Epidemiologist, National CJD Research and Surveillance Unit, University of Edinburgh, Western General Hospital Edinburgh, EH4 2XU

${ }^{*}$ Correspondence to: Anna Molesworth

Email: anna.molesworth@ed.ac.uk;

Tel: +44(0)1315371980
}

\section{Online article number E19}

Refereed Paper - accepted 18 September 2012

DOI: 10.1038/sj.bdj.2012.1089

${ }^{\circledR}$ British Dental Journal 2012; 213: E19 through dentistry, and despite a widespread tissue distribution, abnormal prion protein (thought to be responsible for the transmission of prion diseases) has not been detected in human gingival or pulpal tissue. $^{8-10}$ Nonetheless, data from animal studies suggest the potential for transmission of prion diseases via contaminated oral tissues/secretions. ${ }^{11-13}$ Other possible routes of transmission may include the use of human dura mater graft material ${ }^{14}$ or bovine derived implantable material ${ }^{15}$ during dental procedures. Moreover, although the incubation period in vCJD is likely to be between 10-20 years, shorter periods have been noted in transfusion-associated cases and might also be the case for other iatrogenic routes. These observations, the high frequency of operative dental interventions in the UK, the possibility of prion transmission through protein contamination of dental instruments and technical challenges in implementation of effective instrument decontamination processes in dentistry, have all raised concerns over the potential for vCJD transmission from one person to another, from the re-use of contaminated instruments in the dental setting, depending on the tissues involved and instruments used. ${ }^{16-21}$
Case-control studies have considered dentistry as a potential risk factor for the more common sporadic form of CJD, although none have found evidence of statistically significant associations. ${ }^{22-24} \mathrm{~A}$ previous study in the UK found no associations between reported dental treatment and risk of vCJD. ${ }^{25}$ However the previous study relied on information from the patients' relatives regarding the dental histories of the cases and concluded that examination of dental records by qualified dental professionals may provide more accurate data. The aim of the current study was therefore to use previously unpublished information obtained directly from the dental records, in a new analysis to assess the risk of vCJD associated with dental treatment.

\section{PARTICIPANTS AND METHODS}

In Great Britain, cases of CJD have been referred to the UK National CJD Research and Surveillance Unit (NCJDRSU) since $1990 .{ }^{26}$ Our dental study took place in 2008-2009. It involved, primarily, a casecontrol study of dental treatment histories in vCJD cases and general population control subjects who had been registered at a general dental practice, with or without 
a history of treatment, for at least some of the time before clinical onset/interview. A separate investigation of geographic and temporal links between vCJD cases who had attended the same dental practice before onset was also undertaken. Additional information was sought on use of human dura mater graft material and bovine derived bone products in dentistry.

\section{Study participants}

All cases of vCJD classified as 'definite' or 'probable' according to standard diagnostic criteria, ${ }^{27}$ who were resident in Great Britain at onset of clinical symptoms and referred to NCJDRSU between May 1995 and August 2009 ( $\mathrm{n}=165)$, were considered eligible for inclusion in the study. The control group ( $\mathrm{n}=851)$ for the dental study was recruited in 2003 as a random sample of individuals from the general population. Control selection is described in greater detail by Ward et al. ${ }^{3}$ elsewhere. In summary, 4,400 addresses were selected from a random sample of 100 postcode sectors, the latter which were selected to have a regional distribution similar to that of vCJD cases and to represent the population of Great Britain in terms of urban/rural and socio-economic status. One individual was randomly sampled in each household using an age-weighted procedure to ensure a sufficient number of younger people to provide a comparison group for VCJD cases (the highest incidence of vCJD is in those aged 10-39 years ${ }^{26}$ ), as well as separate use for analysis with sporadic CJD cases who tend to be older. For both cases and control subjects, individuals were enrolled as participants into this study after informed consent was obtained for their dental records to be accessed. Consent was obtained for cases from a relative at an interview following initial referral and from control subjects at the time of recruitment. Lothian Multi-Centre Research Ethics Committee approved the study.

\section{Data collection}

In the UK, a patient's dental record comprises their registration details and treatment history at the current dental practice; the record does not usually follow the patient if the patient moves practice. Attempts were made to retrieve dental registration and treatment records from general dental practitioners (GDPs) with whom cases

Table 1 Availability of dental records for variant Creutzfeldt-Jakob Disease (vCJD) cases and control subjects, by source. Participants are consenting individuals whose dental history we

tried to obtain. Numbers include three probable blood transfusion-associated cases of vCJD

\begin{tabular}{|l|l|l|}
\hline & $\begin{array}{l}\text { Number of } \\
\text { vCJD Cases (\%) }\end{array}$ & $\begin{array}{l}\text { Number of } \\
\text { Controls (\%) }\end{array}$ \\
\hline Total eligible individuals & 165 & 851 \\
\hline Non-consenters & 5 & 267 \\
\hline Participants & $160(100 \%)$ & $584(100 \%)$ \\
\hline $\begin{array}{l}\text { Participants with GDP and/or NHS records available by } \\
\text { time before onset (cases)/interview (control subjects) }\end{array}$ & $78(48.8 \%)$ & $457(78.3 \%)$ \\
\hline $0-4$ yrs & $75(46.9 \%)$ & $441(75.5 \%)$ \\
\hline $5-9$ yrs & $35(21.9 \%)$ & $290(49.7 \%)$ \\
\hline $10-14$ yrs & $27(16.9 \%)$ & $144(24.7 \%)$ \\
\hline $15-19$ yrs & $15(9.4 \%)$ & $72(12.3 \%)$ \\
\hline $20+$ yrs & $7(4.4 \%)$ & $32(5.5 \%)$ \\
\hline $\begin{array}{l}\text { Participants with GDP records available for some time } \\
\text { before onset/interview }\end{array}$ & $55(34.4 \%)$ & $384(65.8 \%)$ \\
\hline $\begin{array}{l}\text { Participants with NHS records available for some time } \\
\text { before onset/interview }\end{array}$ & $36(22.5 \%)$ & $113(19.3 \%)$ \\
\hline $\begin{array}{l}\text { Participants with both GDP and NHS records available } \\
\text { for some time before onset/interview }\end{array}$ & $13(8.1 \%)$ & $41(7.0 \%)$ \\
\hline
\end{tabular}

and control subjects had been registered since 1980 (before which time exposure to the BSE-agent is thought unlikely to have occurred). In order to identify the GDPs for cases, the contact details of the current GDP and a brief dental history were obtained from a close family member around the time of diagnosis. All families of vCJD cases were also sent a letter at the start of the study requesting any further information. In addition, information was used from public-health investigations that had been previously carried out in respect of cases, with family consent. For control subjects, details of their current GDP were obtained from the control at the time of recruitment interview. Partial information was supplemented using Postcode Plus ${ }^{\circledR}$ software (AFD Software Ltd, Ramsey, Isle of Man) and internet searches. Failure to obtain a full dental history led to attempts to identify GDPs via dental treatment payment schedules recorded by National Health Service (NHS) Dental Practice Boards (including the NHS Business Services Authority Dental Practice Division for England and Wales, and NHS National Services Scotland Practitioner Services Division). GDP's were not aware of case-control designation.

The dental records of participants were collected and scrutinised by two dental healthcare workers. Registration and treatment data, including routine as well as specialist procedures, were recorded from GDP records where available and from NHS payment data when GDP records were not available. The number and dates of treatments were recorded for each participant using a structured questionnaire developed from initial pilot work. Data were double entered, validated and stored in a secure database (Microsoft Visual FoxPro 5.0) for subsequent analyses.

\section{Analysis}

The association between type of dental treatment and vCJD was assessed by examining differences in case-control status between participants exposed and not exposed to a specific dental treatment since 1980 and before onset (for cases) or interview (for controls), among those for whom dental records were available for at least some of this time. These included dental patients who had received treatment, and those registered without treatment. Information on the GDP(s) attended were also cross-referenced to determine whether any cases had visited the same dental practice, and if so, dental records were examined for type and timing of treatments. Where dental records were not available, we could not assume there had been no dental care, since a dentist's details or a history of treatment may still have been reported by the relatives at interview; we 
Table 2 Risk of variant Creutzfeldt-Jakob Disease (vCJD) by dental treatment before onset (cases)/interview (control subjects)

\begin{tabular}{|l|l|l|l|l|} 
Characteristic & $\begin{array}{l}\text { Number of } \\
\text { vCJD cases (\%) } \\
n=76\end{array}$ & $\begin{array}{l}\text { Number of } \\
\text { controls }(\%) \\
n=457\end{array}$ & $\begin{array}{l}\text { Adjusted OR } \\
(95 \% \mathrm{CI})\end{array}$ & p-value \\
\hline Sex &
\end{tabular}

Sex

\begin{tabular}{|l|l|l|l|l|l|l}
\hline Male & 39 & $(51.3)$ & 216 & $(47.3)$ & & \\
\hline Female & 37 & $(48.7)$ & 241 & $(52.7)$ & & \\
\hline
\end{tabular}

Birth cohort

\begin{tabular}{|l|l|l|l|l|l|l}
\hline 1939 or earlier & 0 & $(0)$ & 43 & $(9.4)$ & & \\
\hline $1940-1949$ & 5 & $(6.6)$ & 42 & $(9.2)$ & & \\
\hline $1950-1959$ & 4 & $(5.3)$ & 39 & $(8.5)$ & & \\
\hline $1960-1969$ & 18 & $(23.7)$ & 92 & $(20.1)$ & & \\
\hline $1970-1979$ & 30 & $(39.5)$ & 116 & $(25.4)$ & & \\
\hline $1980-1989$ & 19 & $(25.0)$ & 102 & $(22.3)$ & & \\
\hline $1990-1999$ & 0 & $(0)$ & 23 & $(5.0)$ & & \\
\hline Dental treatment & & & & & \\
\hline Routine & & &
\end{tabular}

\begin{tabular}{l|l|l|l|l|l|l}
\hline Basic periodontal examination & 20 & $(26.3)$ & 140 & $(30.6)$ & $0.73(0.38,1.40)$ & 0.34 \\
\hline Minimal fillings & 45 & $(59.2)$ & 316 & $(69.1)$ & $0.59(0.35,1.00)$ & 0.05 \\
\hline Extensive fillings & 47 & $(61.8)$ & 280 & $(61.3)$ & $1.09(0.64,1.84)$ & 0.76 \\
\hline Non-surgical extractions & 36 & $(47.4)$ & 171 & $(37.4)$ & $1.38(0.82,2.31)$ & 0.22 \\
\hline Root canal treatment & 9 & $(11.8)$ & 95 & $(20.8)$ & $0.45(0.21,1.00)$ & 0.05 \\
\hline Other minor oral surgery & 4 & $(5.3)$ & 19 & $(4.2)$ & $1.47(0.50,4.36)$ & 0.49 \\
\hline Periodontal treatment & 56 & $(73.7)$ & 353 & $(77.2)$ & $0.66(0.35,1.23)$ & 0.19 \\
\hline Specilist & & & & & &
\end{tabular}

\begin{tabular}{l|l|l|l|l|l|l}
\hline Specialist & 0 & $(0)$ & 2 & $(0.4)$ & & \\
\hline Periodontal surgery & 3 & $(3.9)$ & 24 & $(5.3)$ & $0.67(0.20,2.34)$ & 0.53 \\
\hline Surgical extractions & 0 & $(0)$ & 1 & $(0.2)$ & & \\
\hline Implant surgery & 0 & $(0)$ & 0 & $(0)$ & & \\
\hline Sinus lifts & 0 & $(0)$ & 12 & $(2.6)$ & & \\
\hline Oral mucosal disease & & & & & & \\
\hline
\end{tabular}

Other procedures

\begin{tabular}{l|l|l|l|l|l|l}
\hline Botox & 0 & $(0)$ & 0 & $(0)$ & & \\
\hline Dermal fillers & 0 & $(0)$ & 0 & $(0)$ & & \\
\hline Intravenous sedation & 2 & $(2.6)$ & 9 & $(2.0)$ & $0.70(0.13,3.59)$ & 0.67 \\
\hline Haemostasis & 1 & $(1.3)$ & 6 & $(1.3)$ & $0.83(0.11,6.28)$ & 0.86 \\
\hline Orthodontics & 11 & $(14.5)$ & 38 & $(8.3)$ & $1.73(0.75,3.97)$ & 0.20 \\
\hline Other & 21 & $(27.6)$ & 163 & $(35.7)$ & $0.73(0.41,1.30)$ & 0.28 \\
\hline
\end{tabular}

Dental treatment definitions: routine comprised basic periodontal examination (routine examination); minimal fillings (buccal, occlusal, incisal edge type, all non-lab-constructed restorations); extensive fillings (those that may traumatise gingival/periodontal tissues, all lab-constructed restorations); non-surgical extractions (all teeth/roots extracted not surgically removed); root canal treatment; minor oral surgery (not extractions or periodontal treatment, may include dry socket, hemisection, apicectomy, buried roots, exposing teeth); periodontal treatment (general
scale and polish or root debridement). Specialist: comprised periodontal surgery (not general scale and polish or root debridement, may includ gingivectomy, raise flaps, guided tissue regeneration); surgical extractions (surgical removal of teeth); implant surgery (non-restorative work, may include guided surgery, atraumatic extraction and implant insertion); sinus lifts; oral manifestations (may include ulceration, stomatitis lichen planus, leukoplakia, candidosis, herpetic lesion, keratosis, ANUG). Other procedures: comprised botox injections, dermal fillers, intravenous sedation, haemostasis (using surgical or equivalent), orthodontics (fixed and/or removable), other emergency visits not recorded elsewhere (may include prescription, recement crown/loridge, dressing, pericoronitis, suture removal). Two cases who had probably acquired their infection
via vCID implicated blood components were excluded from the case-control analyses on the basis that they would not have been infected via via vCJD implicated blood components were excluded from the case-control analyses on the basis that they would not have been infected via dental route; Odds Ratio (OR) with $95 \%$ confidence interval (C) is the ratio of odds for $\mathrm{VCD}$ in patients wit
specified treatment, adjusted for sex, birth cohort and region of onset (cases)/interview (control subjects). instead excluded these data as missing.

Because the control sample had been selected to allow for separate comparison with sporadic CJD cases, the median age of the control subjects included in the casecontrol analysis (31 years) was greater than that of the vCJD cases (26 years). This age difference was accounted for in the analysis. Logistic regression was used, adjusting for effects of sex, birth cohort and region of onset (cases)/interview (control subjects). The magnitudes of associations were assessed by the odds ratio (OR) for vCJD in those with a specific dental treatment compared to those without that treatment, with a 95\% confidence interval (95\% CI). Data were analysed using STATA/IC 8.0 (StataCorp, College Station, Texas, USA).

\section{RESULTS}

A total of 165 cases and 851 control subjects were considered eligible for inclusion in the dental study; consent for dental records to be reviewed was obtained from 160 and 584 respectively.

Availability of dental records for study participants is summarised by source in Table 1. Full or partial pre-onset/interview dental records were available for fewer cases (49\%, 78 out of 160) than control subjects (78\%, 457 out of 584); the main reason for not obtaining dental records was that the patient and/or their GDP could not be traced. The majority of data were for less than five years before onset/interview, with highest rates of dental record retrieval from the late 1990s for cases and the early 2000s in control subjects (not shown). Before 1990, fewer than $15 \%$ of cases and control subjects had GDP records for any single year. Detailed NHS data were only available from 1996 in England and Wales, and 1999 in Scotland.

Dental treatments and associated risks of vCJD are presented along with basic demographic information in Table 2 for vCJD cases compared with control subjects for whom dental records before clinical onset/ interview were available. Results showed that there was no evidence that vCJD cases experienced an excess of any type of dental treatment. However, the risks associated with a history of root canal treatment (OR 0.45; 95\% CI 0.21-1.00) or minimal fillings (OR 0.59; 95\% CI 0.35-1.00) suggested a statistically borderline $(p=0.05)$ effect. 
Two cases had attended the same dental practice; both cases had a history of multiple treatments which included routine extractions, fillings and periodontal treatment. At their closest the cases were treated approximately one month apart in both 1989 and 1991; at no time point were they treated on the same day. Disease onset occurred in 1996 and 1999, respectively.

The use of human dura mater graft material or bovine derived bone products were not detected in records of vCJD cases or controls.

\section{DISCUSSION}

This study could provide no evidence of an association between dental treatment and vCJD. The case-control review of specific dental treatments showed that vCJD cases were no more likely to have undergone any dental treatment than population control subjects. Although dental transmission could, theoretically, have occurred between the two cases treated at the same practice from the re-use of contaminated instruments, we propose that this route is unlikely considering the probable number of instrument decontamination cycles between contacts. Although there was no detailed information available on decontamination processes in the practice, it is likely that this was similar to that reported previously for UK dental practice at that point in time. ${ }^{16-18}$ Modelling scenarios for transmission of infection by surgical instruments ${ }^{28}$ suggest the risk of transmitting infection drops dramatically for subsequent patients, and instruments that have gone through ten or more cycles of decontamination have a lower probability of transmitting infection. The two cases also had other factors in common besides dentistry which might have increased the risk of acquiring vCJD rather than dental risks per se: they had lived on the same street, attended the same school and purchased meat from the same butchers. Previous public health investigations of these links have, however, identified no circumstances that may have led to a potential additional risk. ${ }^{29}$ Moreover, there was no statistical evidence of clustering of vCJD cases in this location, and although the two cases lived on the same street, there was only one local GDP in this area, so their attendance at the same practice was perhaps unsurprising. While it is possible that the links between cases occurring at the same dental practice may be compatible with dental transmission, we feel that the most likely explanation is that the cause of vCJD was the same as that of the large majority of other vCJD cases in the UK. No recorded use of human dura mater graft material or bovine derived bone products was detected in vCJD cases or control subjects; no information is currently available on the extent of use of these agents in UK dentistry, although anecdotal evidence suggests that quantities would have been low.

Definitive conclusions cannot, however, be drawn, since dental records were not obtained for a large proportion of participants, with substantial differences in the completeness of information between cases and control subjects. Our ability to obtain complete dental histories for both cases and control subjects was limited by lack of UK requirements to keep lifetime dental records for patients. This study, at best, traced approximately 50\% of records in a given year, with increasingly poor availability of dental records for less recent time periods; a relatively complete dental history was a very rare occurrence. The poor availability of data means the study had only $72 \%$ power to detect factors associated with a doubling of risk, assuming $25 \%$ of the control population had received dental treatment. Moreover, the increasingly poor recovery of dental records more than five years before onset/ interview, limits identification of risk-factors other than those associated with relatively short incubation periods. As a result, the vCJD risk associated with specific types of dental treatment or with dentistry as a whole may have been underestimated or even missed.

Obtaining data for cases was also less successful than for control subjects, which may have been due to a generally earlier year of interview for the relatives of cases (77\%, 123 out of 160 interviewed before 2003) than for the relatives of control subjects (2003), as well as the fact that the majority of cases (98\%, 157 out of 160) had died by the time dental records were requested in 2008-2009. It is also possible that control subjects were better able to identify their own GDP, than for cases (which relied on relatives). The selection bias thus introduced could have undermined the results and may, for example, explain the borderline effect that was associated with root canal treatment or minimal fillings. Infection via the dental route as a consequence of poor dental health has been proposed as a potential risk factor for vCJD in the UK. ${ }^{30}$ In our study the reasons for any protective effect associated with dental treatment are unclear; however, we feel this was more likely to arise from the large differences in the availability of data between cases and controls, than a true protective effect.

Unfortunately, the large volume of missing data meant it was not possible to undertake analysis by time between treatment and onset (cases) or interview (controls), or restrict the analysis to those cases whose relatives were interviewed relatively close in time to the control interviews, which may have reduced the potential for bias to arise. For the same reason, although we took region, age and sex into account, we did not adjust for effects of additional confounding by, for example, socio-economic status, diet or other medical risks. Moreover, had we assumed that where dental records were not available the subject was untreated, instead of excluding these data as missing, these limitations would remain. We therefore recognise that significant differences in dental treatment between cases and control subjects, as well as instances where cases have attended the same GDP, may have been missed.

Despite these limitations, this study has generated a unique dataset of dental treatment histories of vCJD cases, and is the first and largest study undertaken of dental records investigating links between treatment and development of vCJD. Misclassification of dental treatments and bias in their recall by relatives is not an issue as it has been in previous studies, since qualified dental professionals classified treatments based directly on dental notes. While we recognise that selection bias was a problem, alternative methods of selecting controls are not without their own limitations; and the general population control group has proved the most successful in terms of numbers recruited and response rate. ${ }^{3}$ In addition, the methodology employed by this study resulted in good cooperation from GDPs, even if it 
remains apparent that in Great Britain the current system on quality and retention of dental records, with accompanying inability to trace patient records, does not lend itself to identifying dental exposures that have occurred in the past. We hope that this study can highlight this problem and influence a change in current practice, with consideration given to the development of an efficient system of dental record keeping that can follow the patient between dental practices, providing an accurate treatment record in a format that can be used to investigate links between dental treatment and transmission of infection.

In summary, this study provided no evidence of a VCJD risk associated with dental treatment. However definitive conclusions cannot be drawn, since it was not possible to obtain complete dental histories for either cases or control subjects, resulting in possible bias in the results, and inadequate power to detect underlying vCJD risk. Given the potentially long incubation period of vCJD, true quantification of the risk of dental transmission can only be achieved if full dental histories of every patient are preserved. For now, the limited information on dental history in cases and the possibility that there may be sub-clinical infection, indicate that links between patients infected with VCJD and dental treatment as a possible risk factor for vCJD cannot be excluded. In the UK, if satisfactory standards of decontamination are observed, routine dentistry is understood to be low risk. ${ }^{31}$ In light of the fact that it is difficult to prove or disprove the link between vCJD cases and dental treatment, policies which drive improvements in standards of cleaning and sterilisation of re-usable dental instruments should continue to be supported.
We would like to thank dental practitioners and boards, family members, control subjects and CJD Support Network for their help in the collection of data. CJD surveillance and recruitment to the national case-control study was funded by the Department of Health, UK and Scottish Government Health Department. Additional support for the dental study was given by the Department of Health, UK. The authors report no conflict of interests.

1. Health Protection Agency. Summary results of the second national survey of abnormal prion prevalence in archived appendix specimens. Health Protection Report 2012; 6(32). Available at http:// www.hpa.org.uk/hpr/archives/2012/news.htm\#32

2. Advisory Committee on Dangerous Pathogens (ACDP) TSE Risk Assessment Subgroup. Position statement on occurrence of VCJD and prevalence of infection in the UK population, July 2012. Online article available at https://www.wp.dh.gov.uk/ transparency/files/2012/08/ACDP-statement-vCJDoccurrence-and-prevalence-Jul-2012.pdf

3. Ward H J, Everington D, Cousens S N et al. Risk Factors for variant Creutzfeldt-Jakob disease: a case-control study. Ann Neurol 2006; 59: 111-120.

4. Llewelyn C A, Hewitt P E, Knight R S et al. Possible transmission of variant Creutzfeldt-Jakob disease by blood transfusion. Lancet 2004; 363: 417-421.

5. Peden A H, Head M W, Ritchie D L, Bell J E, Ironside $J$ W. Preclinical VCJD after blood transfusion in a PRNP codon 129 heterozygous patient. Lancet 2004; 364: 527-529.

6. Kurita H, Kurashina K, Honda T. Nosocomial transmission of methicillin resistant Staphylococcus aureus via the surfaces of the dental operatory. Br Dent J 2006; 201: 297-300.

7. Redd J T, Baumbach J, Kohn W, Nainan O, Khristova M, Williams I. Patient-to-patient transmission of hepatitis B virus associated with oral surgery. J Infect Dis 2007; 195: 1311-1314.

8. Ironside J W, McCardle L, Horsburgh A, Lim Z, Head M W. Pathological diagnosis of variant CreutzfeldtJakob disease. APMIS 2002: 110: 79-87.

9. Head M W, Ritchie D, McLoughlin V, Ironside J W. Investigation of PrPres in dental tissues in variant CJD. Br Dent J 2003; 195: 339-343.

10. World Health Organization. WHO tables on tissue infectivity distribution in transmissible spongiform encephalopathies. Geneva: WHO, 2010.

11. Ingrosso L, Pisani F, Pocchiari M. Transmission of the $263 \mathrm{~K}$ scrapie strain by the dental route. J Gen Virol 1999; 80: 3043-3047.

12. Bartz $J$ C, Kincaid A E, Bessen R A. Rapid prion neuroinvasion following tongue infection. J Virol 2003; 77: 583-591.

13. Mathiason C K, Powers J G, Dahmes S J et al. Infectious prions in the saliva and blood of deer with chronic wasting disease. Science 2006; 314: 133-136.

14. Bartolucci E G. A clinical evaluation of freeze dried homologous dura mater as a periodontal free graft material. Study in humans. J Periodontol 1981; 52: 354-361.

15. Wenz $B$, Oesch $B$, Horst M. Analysis of the risk of transmitting bovine spongiform encephalopathy through bone grafts derived from bovine bone. Biomaterials 2001; 22: 1599-1606.

16. Smith A, Dickson M, Aitken J, Bagg J. Contaminated dental instruments. J Hosp Infect 2002 51: 233-235.

17. NHS Scotland, Sterile Services Provision Review Group. Survey of decontamination in general dental practice. Scottish Executive Health Department, 2004.

18. Bagg J, Smith A J, Hurrell D, McHugh S, Irvine G. Pre-sterilisation cleaning of re-usable instruments in general dental practice. BrDent J 2007; 202: E22.

19. Economics and Operational Research Division. Potential vCJD transmission risks via dentistry: an interim review. London: $\mathrm{DH}, 2007$.

20. Department of Health. The dental national decontamination survey 2010. London: DH, 2010.

21. Vassey M, Budge C, Poolman T et al. A quantitative assessment of residual protein levels on dental instruments reprocessed by manual, ultrasonic and automated cleaning methods. Br Dent J 2011; 210: E14.

22. Davanipour Z, Alter M, Sobel E, Asher D, Gajdusek D C. Creutzfeldt-Jakob disease: possible medical risk factors. Neurology 1985; 35: 1483-1486.

23. Van Duijin $C M$, Delasnerie-Laupretre $N$, Masullo $\mathrm{C}$ et al. Case-control study of risk factors of Creutzfeldt-Jakob disease in Europe during 1993-95. Lancet 1988: 351: 1081-1085.

24. Collins S, Law M G, Fletcher A, Boyd A, Kaldor J, Masters C L. Surgical treatment and risk of sporadic Creutzfeldt-Jacob disease: a case control study. Lancet 1999; 353: 693-697.

25. Everington D, Smith A J, Ward H J, Letters S, Will $\mathrm{R} G$, Bagg J. Dental treatment and risk of vCJD case control study. Br Dent J 2007; 202: E19.

26. National CJD Surveillance Unit. Creutzfeldt-Jakob Disease surveillance in the UK: 18th annual report 2009. Edinburgh: The National CJD Research and Surveillance Unit, 2011.

27. National CJD Surveillance Unit. National CJD surveillance diagnostic criteria. Edinburgh: The National CJD Research and Surveillance Unit, 2010.

28. Department of Health. Management of possible exposures to CJD through medical procedures. London: DoH, 2001

29. Molesworth A M, Cousens S N, Noel G O, Ward H J. Variant Creutzfeldt-Jakob disease in the United Kingdom: a countrywide or local risk? J Epidemiol Community Health 2010; 64: 616-621.

30. Burnie R, Salmon R L, Thomas D R, Monaghan N. Does poor dental health have a role in the emergence of variant Creutzfeldt Jakob disease in the United Kingdom? J Dental Hypotheses 2011; 2: 74-82.

31. Advisory Committee on Dangerous Pathogens (ACDP). Transmissible spongiform encephalopathy agents: safe working and the prevention of infection: part 4. Infection control of CJD, VCJD and other human prion diseases in healthcare and community settings. London: Department of Health, 2011. Online article available at http:// www.dh.gov.uk/ab/ACDP/TSEguidance/index.htm (accessed November 2012). 